\title{
Antenatal care dropout and associated factors among mothers delivering in public health facilities of Dire Dawa Town, Eastern Ethiopia
}

Dereje Worku', Daniel Teshome ${ }^{2 *}$, Chalachew Tiruneh², Alemtsehay Teshome ${ }^{1}$, Gete Berihun ${ }^{3}$, Leykun Berhanu ${ }^{3}$ and Zebader Walle ${ }^{4}$

\begin{abstract}
Introduction: More than two-thirds of the pregnant women in Africa have at least one antenatal care contact with a health care provider. However, to achieve the full life-saving potential that antenatal care promises for women and babies, four visits providing essential evidence-based interventions - a package often called focused antenatal care are required. Hence, identifying the factors associated with dropout of maternal health care utilization would have meaningful implications. The study aimed to assess antenatal care dropout and associated factors among mothers delivering in the public health facilities of Dire Dawa town, Ethiopia.
\end{abstract}

Methods: Facility-based cross-sectional study was conducted from January 1 to 30, 2020. Proportionate sampling and simple random sampling techniques were used to select 230 women. Data were collected using a structured and pretested interview administered questionnaire during delivery. The data were entered into Epidata version 3.1 and analyzed using SPSS version 20. A binary logistic regression model with a $95 \%$ confidence interval was used to analyze the results. Bivariable analysis (COR [crude odds ratio]) and multivariable analysis (AOR [adjusted odds ratio]) was used to analyze the results. From the bivariable analysis, variables with a $p$-value $<0.25$ were entered into the multivariable logistic regression analysis. From the multivariable logistic regression analysis, variables with a significance level of $p$-value $<0.05$ were taken as factors independently associated with ANC dropout.

Result: The proportion of antenatal care dropouts was 86 (37.4\%) (95 \% Cl: 31.3-43.9). In logistic regression analyses, those who had no past antenatal care follow up were more likely to have ANC dropout (AOR $=7.89 ; 95 \%$ $\mathrm{Cl}$ : 2.109-29.498) and those who had no professional advice were more likely to have antenatal care dropout ( $A O R=4.6495 \% \mathrm{Cl}:$ 1.246-17.254).

Conclusions: This study indicates that a high number of women had antenatal care dropout. Having no past ANC follow-up and professional advice were the major factors of ANC service utilization dropout. Hence, giving more information during the ANC visit is important to reduce the dropout rate from the maternity continuum of care.

Keywords: ANC, Dropout, Associated factor

* Correspondence: danigreatt19@gmail.com

${ }^{2}$ Department of Anatomy, College of Medicine and Health Sciences, Wollo University, Dessie, Ethiopia

Full list of author information is available at the end of the article

(c) The Author(s). 2021 Open Access This article is licensed under a Creative Commons Attribution 4.0 International License, which permits use, sharing, adaptation, distribution and reproduction in any medium or format, as long as you give appropriate credit to the original author(s) and the source, provide a link to the Creative Commons licence, and indicate if changes were made. The images or other third party material in this article are included in the article's Creative Commons licence, unless indicated otherwise in a credit line to the material. If material is not included in the article's Creative Commons licence and your intended use is not permitted by statutory regulation or exceeds the permitted use, you will need to obtain permission directly from the copyright holder. To view a copy of this licence, visit http://creativecommons.org/licenses/by/4.0/. The Creative Commons Public Domain Dedication waiver (http://creativecommons.org/publicdomain/zero/1.0/) applies to the data made available in this article, unless otherwise stated in a credit line to the data. 


\section{Introduction}

Antenatal care (ANC) is a maternal healthcare service received by pregnant women and adolescent girls from coordinated health care providers to support and sustain the mother's optimal health during pregnancy, delivery, and puerperium with having and rearing of healthy baby [1]. It has been repeatedly shown to reduce maternal and neonatal deaths via identification of high-risk pregnancies [2-7]. Besides, it provides an opportunity for counseling on nutrition, birth readiness, delivery care, and contraception after birth. It is important particularly in settings and subgroups where the socioeconomic and public health resources are constrained $[8,9]$.

The World Health Organization (WHO) describes a world in which "every pregnant woman and newborn obtains high-quality care during gestation, labor, and the postnatal period" [10]. In 2015, however, almost 303,000 women and adolescent girls died as a result of pregnancy and delivery difficulties [11]. The majority of maternal deaths occur in low-resource settings, and the majority can be avoided [12]. The WHO recommended at least four ANC visits for pregnant women in 2002 [13]; however this recommendation was changed to at least eight visits in 2016, with the first ANC visit occurring before the 12th week of pregnancy [1].

In Africa, more than two-thirds of pregnant women had at least one prenatal care visit with a health care practitioner [14]. As per the 2019 EMDHS, 74\% of women giving birth in the five years before to the survey had prenatal care from a skilled practitioner at least once during their previous pregnancy. For their most recent live birth, four out of ten women (43\%) had four or more ANC visits. Women in the urban region were more likely than those in the rural area to have had ANC from a skilled provider ( 85 and $70 \%$, respectively) and to have had four or more ANC visits (59 and 37\%, respectively) [15]. In Ethiopia and Dire Dawa, the proportion of ANC dropout was 44.58 and $27.4 \%$, respectively [16]. Over a 14-year period, the percentage of women receiving prenatal care from a skilled provider has increased by $46 \%$ points, from $28 \%$ to 2005 to $74 \%$ in 2019 [15]. While there has been significant progress in Ethiopia in terms of at least one ANC attendance [17, 18 , attendance of the recommended visits has been suboptimal [19, 20].

A study conducted on ANC utilization during Corona virus disease 2019 (COVID-19) revealed that only $29.3 \%$ of pregnant women had fully utilized antenatal care services during the pandemic period. Mother age $\geq 35$ years secondary education and above history of stillbirth before recent pregnancy, interruption and diversion of services due to COVID-19 response, fear of COVID-19, and lack of transport access were predictors of full antenatal care service utilization [21].
A different cross-sectional study conducted in Ethiopia shows that the key factors of four or more antenatal care services utilization were receiving a high quality of ANC care, having high income, living with a short distance from the health facility, women involving in the household decision making, having a small family size, having good knowledge concerning ANC service, and positive attitude towards ANC services [21-26]. Some studies also showed that age, educational status, occupation; planned recent pregnancy, previous ANC visit, and autonomy on healthcare decision making were found to be significantly associated with ANC utilization [27-29].

It's known that adequate utilization of the recommended antenatal care visits is important to improve both the health of the mother and the unborn baby. However, there is limited finding on why women fail to use the recommended subsequent ANC visits in Ethiopia especially in the study area. As a result, a context-specific study is important since the country have diversified population based on (ethnicity, culture, belief and religious). Hence, identifying the factors associated with ANC service utilization dropout would have meaningful for intervention. Therefore, this study aimed to assess ANC dropout and associated factors among mothers delivering in public health facilities of Dire Dawa city town.

\section{Methods and materials Study Area}

The study was conducted at Dire Dawa; it is one of the Federal city administrations in Ethiopia which is located in the eastern part of Ethiopia, $515 \mathrm{Km}$ from Addis Ababa, the capital city of Ethiopia, and $333 \mathrm{Km}$ from the international port of Djibouti. According to the 2019 population projection, Dire Dawa Administration has 493,000 total populations with $49 \%$ males and $51 \%$ females, out of which around 15,346 were women in the reproductive age group. $68.23 \%$ of the population was urban residents. Dire Dawa administration has 2 Hospitals and 8 Urban Health Centers [30]. All the health centers provide ANC service. There is an average of 4 nurses and 3 midwives that provides ANC services in each health centers.

\section{Study Design and study period}

A facility-based cross-sectional study was employed among mothers who gave delivery in public health facilities of Dire Dawa town from January 1-30, 2021. Therefore, mother who gave delivery at the public health facilities of Dire Dawa town were included in the study. On the other hand mothers who were critically ill and those who were not volunteer to participate were excluded from the study. 


\section{Study Population}

All mothers who gave birth at the public health facilities of Dire Dawa town.

\section{Sample Size Determination}

The sample size was calculated using single population proportion formula: $\mathrm{n}=(\mathrm{Z} \alpha / 2)^{2}$ " $\mathrm{p}(1-\mathrm{p}) / \mathrm{d}^{2}$, considering the following assumptions: prevalence rate of ANC service utilization dropout was taken $44.3 \%$ from EDHS 2014, $95 \%$ confidence interval, $5 \%$ margin of error and correction formula. Hence, the total sample size became 230.

\section{Sampling procedure}

Among government health facilities in Dire Dawa town, all health centers in the town were included in the study. The sample size for all health centers was determined according to the principle of proportionate probability technique. The study was conducted in each selected health center to find and register those women who are eligible according to inclusion criteria. Thus, the total participants were identified and the sampled women from each sampling frame were selected using a simple random sampling and the first respondent selected by lottery method while the remaining participants of the study were selected using a systematic sampling technique and a questionnaire was administered to a total of 230 identified delivering mother (Fig. 1).

\section{Data collection tools and procedures}

A pre-tested and structured interviewer-administered questionnaire was used for data collection. Standard questionnaires from EDHS and other similar research done were used [17, 22, 27]. According to the sample allocated to each health center, data was collected during delivery in the selected public health facilities of Dire Dawa town after the pre-test was done in Dil Chora referral hospital. Two Midwives were assigned to collect the data and two BSc degree nurses were supervising data collectors in the process of data collections. However, the sole responsibility of facilitating the whole process was carried out by the principal researcher. The quality of data was assured by using a standard questionnaire from EDHS and other similar research done then translated into Amharic, Afan Oromo, and Somali language. Training was given to the data collectors and supervisors for 2 days on techniques of data collection, data collection material, and purpose of research. Supervision was carried out daily to check data completeness and consistency by both the supervisor and the principal investigators to assure the quality of data.

\section{Data Entry and Analyses}

Data were cleaned, coded, and entered into Epi-info version 7.1 then exported to SPSS version 20 for analysis. A descriptive analysis was carried out to see the distribution of independent variables. A binary logistic regression model with a $95 \%$ confidence interval was used to analyze the results. Bivariable analysis (COR) and multivariable analysis (AOR) was used to analyze the results. From the bivariable analysis, variables with a $p$-value $<$ 0.25 were entered into the multivariable logistic regression analysis. From the multivariable logistic regression analysis, variables with a significance level of $p$-value < 0.05 were taken as factors independently associated with ANC dropout. Model fitness was checked using Hosmer and Lemeshow goodness of fittest, and a p-value $\leq 0.05$ with $95 \%$ confidence interval for Adjusted odds ratio (AOR) was used to determine factors associated with dropout from ANC services.

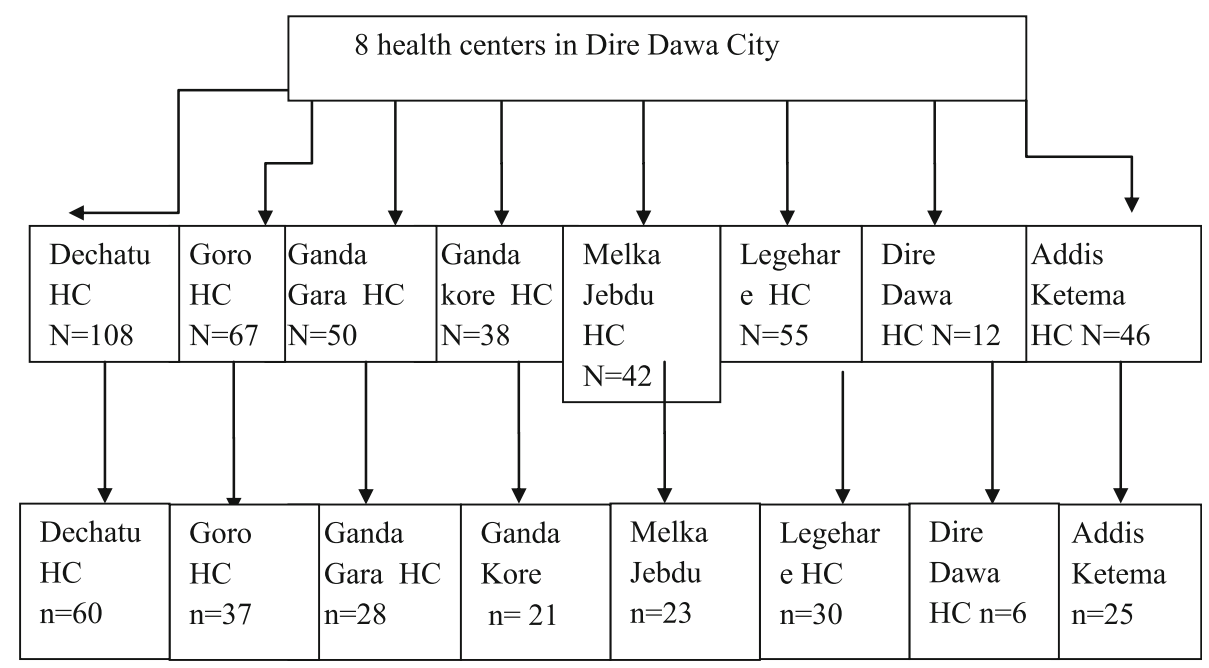

Fig. 1 Proportionate fraction of sample size of each health centers of Dire Dawa Town, $2020(n=230)$ 


\section{Operational Definition}

\section{ANC dropout}

Mothers who did not complete full recommended visit during their pregnancy (a minimum of 4 visits for normal pregnancy) [14].

\section{Antenatal care (ANC)}

$\mathrm{ANC}$ is the care given to a pregnant woman with the aim of improving the maternal and prenatal outcome. ANC includes measuring blood pressure and weights of a woman and taking physical examination, measuring of uterus height and vaccination [31].

\section{Quality of service}

Respondents were asked whether they had been advised of complications or received certain screening tests during at least one of their antenatal visits [32].

\section{Satisfaction}

Self reported level of satisfaction stated as satisfied or dissatisfied on exist interviewed of the ANC service received from health professionals [32].

\section{Results}

\section{Socio demographic characteristics}

A total of 230 mothers participated in this study with a $100 \%$ response rate. Eighty-nine $(38.7 \%)$ of them were in the age group of 25-29. More than one-third $81(35.2 \%)$ of the respondent's husband's educational status was completed secondary school. Out of the study participants, 79 (34.3\%) had completed primary school followed by secondary school 69 (30\%). The majority of the respondents were Muslim 136(59.1\%) followed by Orthodox 77 (33.5\%). Regarding their ethnicity and occupation, the majority of them were Oromo 129 (56.1\%) and housewives 167 (72.6\%), respectively (Table 1).

Table 1 Socio-demographic Characteristics of the respondents in Dire Dawa town, Ethiopia $2020(n=230)$

\begin{tabular}{|c|c|c|c|}
\hline & Characteristics & Frequency & Percentage \\
\hline \multirow[t]{5}{*}{ Age } & $15-19$ & 16 & 7.0 \\
\hline & $20-24$ & 88 & 38.3 \\
\hline & $25-29$ & 89 & 38.7 \\
\hline & $30-34$ & 14 & 6.1 \\
\hline & $35-39$ & 23 & 10.0 \\
\hline \multirow[t]{4}{*}{ Husband educational status } & No formal Education & 26 & 11.3 \\
\hline & Primary & 53 & 23.0 \\
\hline & Secondary & 81 & 35.2 \\
\hline & Diploma and above & 70 & 30.4 \\
\hline \multirow[t]{4}{*}{ Pregnant women educational status } & No formal Education & 52 & 22.6 \\
\hline & Primary & 79 & 34.3 \\
\hline & Secondary & 69 & 30.0 \\
\hline & Diploma and above & 30 & 13.0 \\
\hline \multirow[t]{3}{*}{ Religion } & Orthodox & 77 & 33.5 \\
\hline & Muslim & 136 & 59.1 \\
\hline & Protestant & 17 & 7.4 \\
\hline \multirow[t]{5}{*}{ Ethnicity } & Oromo & 129 & 56.1 \\
\hline & Amhara & 46 & 20.0 \\
\hline & Tigrie & 8 & 3.4 \\
\hline & Guragie & 31 & 13.5 \\
\hline & Somali & 16 & 7.0 \\
\hline \multirow[t]{5}{*}{ Occupation } & House wife & 167 & 72.6 \\
\hline & Civil servant & 29 & 12.6 \\
\hline & Merchant & 21 & 9.1 \\
\hline & Student & 11 & 4.8 \\
\hline & Other & 2 & 0.9 \\
\hline
\end{tabular}




\section{Obstetric condition}

More than half $151(65.7 \%)$ of the pregnant mothers were multigravida. Out of this, $79(52.3 \%)$ had past ANC follow up. Among mothers who had attended for ANC, 56 (70.9\%) of them received ANC service from the health center. Out of the total respondents who had past ANC follow up, the majority $69(87.3 \%)$ of them delivered at the health centers. Among the participants who attended ANC for the current pregnancy, 144 (62.6\%) of them were started their ANC visit in the first trimester followed by the second trimester 81 (35.2\%). The prevalence of ANC dropout was 86 (37.4\%) (Table 2).

\section{Quality of ANC Services}

Concerning the quality of service, $121(52.6 \%)$ of them had satisfied with the service they had received. Out of the respondents, 159 (69.1\%) of them prefer the health center because of its accessibility to transportation. The majority of the respondent 196 (85.2\%) got advice from professionals (Table 3).

\section{Associated factors of ANC dropout}

Binary logistic regression analysis was used to identify associated factors with ANC service utilization dropout. Past ANC follow-up, a number of family size, planned/ supported pregnancy, and professional advice during follow-up were associated in the bivariate analysis but only three (age, past ANC follow-up and professional advice during follow-up) of them were associated in multivariate analysis. Based on the analysis, an age range of 30-39 were less likely to dropout ANC services than those in the age range between 15 and 29 years $(p=$ 0.009 , at $95 \%$ CI; AOR, 0. 387 [0.189, 0.791]). Concerning past ANC condition, the odds of ANC drop out among women who had no past ANC follow up was 7.89 [2.109-29.498] at $95 \%$ CI. Moreover, those who have no professional advice was more likely to have ANC dropout than those who had professional advice $(p=0.022$, at $95 \% \mathrm{CI}:$ AOR, $4.64[1.246-17.254])$ (Table 4).

\section{Discussions}

This study was aimed at assessing ANC utilization dropout and associated factors in the public health facility, Dire Dawa town Ethiopia. The finding of this research showed that the prevalence of ANC dropout was $37.4 \%$. This finding was supported by the survey conducted in Dire Dawa, Ethiopia, where ANC drops out was $44.3 \%$ [33]. However, the current study contradicts a study conducted in Nepal, India, where ANC dropout was $50 \%$ to mean less than the recommended number of ANC services for their recent child pregnancy [34]. This discrepancy might be due to the fact that in Ethiopia the role of Health extension workers is crucial by increasing the level of awareness about ANC for pregnant women by their day to day activities or home to home health education.

In the current study, mothers who had no past ANC follow up was significantly associated with current ANC

Table 2 Obstetric condition of the respondents in Dire Dawa town, Ethiopia $2020(n=230)$

\begin{tabular}{|c|c|c|c|c|}
\hline & & Obstetric condition & Frequency & Percentage \\
\hline \multirow{2}{*}{\multicolumn{2}{|c|}{ Parity }} & Multigravida & 151 & 65.7 \\
\hline & & Primigravida & 79 & 34.3 \\
\hline \multirow[t]{11}{*}{ Multigravida } & \multirow[t]{2}{*}{ Past ANC follow up } & Yes & 79 & 52.3 \\
\hline & & No & 72 & 47.7 \\
\hline & \multirow[t]{3}{*}{ Place of past ANC received } & Health center & 56 & 70.9 \\
\hline & & Hospital & 20 & 25.3 \\
\hline & & Private clinic & 3 & 3.8 \\
\hline & \multirow[t]{4}{*}{ Place of delivery for past pregnancy } & Health center & 69 & 87.3 \\
\hline & & Hospital & 8 & 10.1 \\
\hline & & Home & 2 & 2.5 \\
\hline & & Private clinic & 0 & 0 \\
\hline & \multirow[t]{2}{*}{ Outcome } & Good & 78 & 98.7 \\
\hline & & $\mathrm{Bad}$ & 1 & 1.3 \\
\hline \multirow{3}{*}{\multicolumn{2}{|c|}{ Time of ANC visit for current pregnancy }} & First trimester & 144 & 62.6 \\
\hline & & Second trimester & 81 & 35.2 \\
\hline & & Third trimester & 5 & 2.2 \\
\hline \multirow{2}{*}{\multicolumn{2}{|c|}{ ANC dropout }} & $\leq 3$ visit & 86 & 37.4 \\
\hline & & $\geq 4$ visit & 144 & 62.6 \\
\hline
\end{tabular}


Table 3 Quality of ANC service in the health center of Dire Dawa town, Ethiopia, 2020. $(n=230)$

\begin{tabular}{llll}
\hline Quality of ANC service & & Frequency & Percent \\
\hline Presence of Professional advice during ANC visit & Present & 196 & 34 \\
& Absent & 159 & 65.2 \\
Reason for health center preference & Accessible & 15 & 59.1 \\
& Affordable & 56 & 24.3 \\
Level of satisfaction & Quality of service & 121 & 52.6 \\
& Satisfied & 109 & 47.4 \\
\hline
\end{tabular}

service utilization dropout (AOR $=7.89$; $95 \%$ CI: 2.109 29.498). This finding was in agreement with the study conducted in Womberma Woreda, Northwest Ethiopia $(\mathrm{AOR}=1.92 ; 95 \% \mathrm{CI}: 1.16-3.18)$ [35]. This might be due to the fact that having past experience of ANC follow-up will encourage a pregnant mother to have ANC visits.

On the other hand, the other factor significantly influences utilization of ANC was the absence of professional advice during ANC visit (64.7\%), which was the main cause to increase ANC dropout rate. This finding was comparable with the study carried out in Addis Ababa and Bahir Dar, where no professional advice during ANC visit with the prevalence of 72.4 and $59.9 \%$, respectively [36]. In addition, there was significant association of lack of professional advice with ANC dropout (AOR $=0.216: 95 \%$ CI: $0.058-0.803$ ). This finding was supported by other study conducted in Addis Ababa, where there was significant association (AOR $=64 ; 95 \%$ CI: 1.246-17.254) [37]. Another study conducted in Bahir-Dar special zone revealed that having no professional advice had a significant association to ANC dropout $(\mathrm{AOR}=5.47 ; 95 \% \mathrm{CI}: 3.10-9.65)$ [36]. This might be due to the fact that mothers who had professional advice had a clear understanding about antenatal care, their health condition, and their fetal condition as well that make them complete their ANC follow-up.

\section{Limitation of the study}

The current study was limited to small number of study participants and there was also budget limitation to conduct the study with large sample size. Since the study was conducted in the health centers and COVID-19 era, the result may not be applicable to the whole population of delivering mothers in Ethiopia.

\section{Conclusions}

This study revealed that there is a high number of pregnant women had ANC dropout in the study area. Having no past ANC follow-up and absence of professional advice during ANC visit were the major factors of ANC dropout. Hence, giving more information during the ANC visit is important to reduce the dropout rate from the maternity continuum of care.

Table 4 Association of selected characteristics with number of ANC visits during gestation, Dire Dawa town, Ethiopia 2020 ( $n=230)$

\begin{tabular}{|c|c|c|c|c|c|c|}
\hline \multirow[t]{2}{*}{ Characteristics } & \multicolumn{3}{|c|}{ Number of ANC visits during gestation } & \multirow[t]{2}{*}{ COR $(95 \% \mathrm{Cl})$} & \multirow[t]{2}{*}{ AOR $(95 \% \mathrm{Cl})$} & \multirow[t]{2}{*}{$\mathrm{p}$-value } \\
\hline & & $\geq 4$ & $\leq 3$ & & & \\
\hline \multirow[t]{2}{*}{ Age } & $15-29$ & $128(88.9 \%)$ & $65(75.6 \%)$ & 1 & & \\
\hline & $30-39$ & $16(11.1 \%)$ & $21(24.4 \%)$ & $0.387[0.189-0.791]^{*}$ & $0.387[0.189-0.791]^{*}$ & 0.009 \\
\hline \multirow[t]{2}{*}{ Number of family size } & Two & $50(63.3 \%)$ & $29(36.7 \%)$ & 1 & & \\
\hline & $\geq 3$ & $94(62.3 \%)$ & $57(37.7 \%)$ & $0.219[0.115-0.418]^{*}$ & $0.726[0.282-1.865]$ & 0.24 \\
\hline \multirow[t]{2}{*}{ Past ANC history } & Had ANC & $91(60.3 \%)$ & $60(39.7 \%)$ & 1 & & \\
\hline & No ANC & $53(67.1 \%)$ & $26(32.9 \%)$ & $0.170[0.063-0.455]^{*}$ & $7.89[2.109-29.498]^{* *}$ & 0.002 \\
\hline \multirow[t]{2}{*}{ Current pregnancy planned/supported } & Planned & $142(64 \%)$ & $80(36 \%)$ & 1 & & \\
\hline & Unplanned & $2(25 \%)$ & $6(75 \%)$ & $0.188[0.037-0.957]^{*}$ & $0.326[0.052-2.060]$ & 0.31 \\
\hline \multirow[t]{2}{*}{ Presence of Professional advice during ANC visit } & Present & $134(67.3 \%)$ & $64(32.7 \%)$ & 1 & & \\
\hline & Absent & $12(35.3 \%)$ & $22(64.7 \%)$ & $0.264[0.123-0.568]^{*}$ & $4.64[1.246-17.254] * *$ & 0.032 \\
\hline
\end{tabular}

NOTE $=*$; $p$-value $\leq 0.25$, and **; $p$-value $\leq 0.05$ significant at $95 \% \mathrm{Cl}$ 


\section{Abbreviations}

ANC: Antenatal care; CSA: Central statistical agency; EDHS: Ethiopian demographic health survey; WHO: World health organization

\section{Supplementary Information}

The online version contains supplementary material available at https://doi. org/10.1186/s12884-021-04107-7

\section{Additional file 1:}

\section{Acknowledgements}

We are grateful to Dire Dawa University and Dire Dawa health office for providing the necessary facilities for conducting the research.

\section{Authors' contributions}

DW and DT developed the proposal and collected the data, analyzed and interpreted the results, and was a major contributor in writing the mother document and the manuscript. CT, AT, GB, LB and ZW critically reviewed both the proposal and manuscript and contributed to the study design development and interpretation of the data. All authors read and approved the final manuscript.

\section{Funding}

Not applicable.

\section{Availability of data and materials}

The datasets used and/or analyzed during the current study are available from the corresponding author on reasonable request.

\section{Declarations}

\section{Ethics approval and consent to participate}

Ethical clearance was obtained from Ethical Review Committee of Dire Dawa University, College of Medicine and Health Sciences, and then cooperation letters was sent to Dire Dawa health office and each health centers. The purpose and objective of the study were explained to the director of each health centers. All study participants were informed about the purpose and confidentiality issues related to the study. Participation was voluntary. The verbal informed consent was obtained from each participant's who could not able to read and write, and the verbal informed consent was approved by the Ethical Review Committee of Dire Dawa University, College of Medicine and Health Sciences, and Dire Dawa Health Office. Written informed consent was obtained from each participant who could able to read and write. For minor participants, informed consent was obtained from their husband and relatives. Finally, the data were collected and confidentiality of client information was maintained. Lastly, the authors confirmed that this study was conducted in accordance with the declaration of Helsinki.

\section{Consent for publication}

Not applicable.

\section{Competing interests}

The authors declare that they have no competing interests.

\section{Author details}

${ }^{1}$ Department of Gynecology and Obstetrics, College of Medicine and Health Sciences, Wachamo University, Hossana, Ethiopia. '2Department of Anatomy, College of Medicine and Health Sciences, Wollo University, Dessie, Ethiopia. ${ }^{3}$ Department of Environmental Health, College of Medicine and Health Sciences, Wollo University, Dessie, Ethiopia. ${ }^{4}$ Department of Public Health, College of Health Sciences, Debre Tabor University, Debre Tabor, Ethiopia.

Received: 11 February 2021 Accepted: 6 September 2021 Published online: 15 September 2021

\section{References}

1. World Health Organization. WHO recommendations on antenatal care for a positive pregnancy experience. Geneva: WHO; 2016
2. AbouZahr C, Wardlaw T. Antenatal care in developing countries: promises, achievements and missed opportunities - an analysis of trends, levels and differentials, 1990-2001. In: World Health Organization; 2003.

3. Dixit P, Dwivedi LK, Ram F. Strategies to improve child immunization via antenatal care visits in India: a propensity score matching analysis. PLoS One. 2013;8:e66175.

4. Pervin J, et al. Association of antenatal care with facility delivery and perinatal survival - a population-based study in Bangladesh. BMC Pregnancy Childbirth. 2012;12:111.

5. Aminu M, et al. Causes of and factors associated with stillbirth in low- and middle-income countries: a systematic literature review. BJOG. Int J Obstet Gynaecol. 2014;121:141-53.

6. Campbell OM, Graham WJ. Strategies for reducing maternal mortality: getting on with what works. Lancet. 2006;368:1284-99.

7. Petrou S, Kupek E, Vause S, Maresh M. Antenatal visits and adverse perinatal outcomes: results from a British population-based study. Eur J Obstet Gynecol Reprod Biol. 2003;106:40-9.

8. Reynolds HW, Wong EL, Tucker H. Adolescents' use of maternal and child health services in developing countries. International family planning perspectives. 2006 Mar 1:6-16.

9. Nisar N, White F. Factors affecting utilization of antenatal care among reproductive age group women (15-49 years) in an urban squatter settlement of Karachi. Journal of Pakistan Medical Association. 2003:53(2):47.

10. Tunçalp Ö, Were WM, MacLennan C, Oladapo OT, Gülmezoglu AM, Bahl R et al. Quality of care for pregnant women and newborns-the WHO vision. BJOG. 20

11. Alkema L, Chou D, Hogan D, Zhang S, Moller A-B, Gemmill A et al.; United Nations Maternal Mortality Estimation Inter-Agency Group collaborators and technical advisory group. Global, regional, and national levels and trends in maternal mortality between 1990 and 2015, with scenario-based projections to 2030: a systematic analysis by the UN Maternal Mortality Estimation InterAgency Group. Lancet. 2016;387(10017):462-74.

12. Maternal mortality. Fact sheet No. 348; Geneva: World Health Organization; 2014

13. Villar J, P B. WHO antenatal care randomized trial: Manual for the implementation for the new model. 2002.

14. World Health Organization. Trends in maternal mortality: 1990-2015: estimates from WHO, UNICEF, UNFPA, World Bank Group and the United Nations Population Division. World Health Organization; 2015.

15. Indicators K. Ethiopia Mini Demographic and Health Survey. 2019

16. Muluneh AG, Kassa GM, Alemayehu GA, Merid MW. High dropout rate from maternity continuum of care after antenatal care booking and its associated factors among reproductive age women in Ethiopia, Evidence from Demographic and Health Survey 2016. PloS one. 2020 Jun 12;15(6): e0234741.

17. CSA. Ethiopia Demographic and Health Survey 2011 Demographic surveillance Addis Ababa, Ethiopia and Calverton,Maryland. USA: CSA; 2011.

18. CSA. Ethiopian Demographic and Health Survey 2016.

19. Melaku Y, Weldearegawi B, Tesfay F, Abera S, Abraham L, Aregay A, et al. Ethiopia BMC Pregnancy and Childbirth. 2014;14:418.

20. Birmeta K, Dibaba Y, Woldeyohannes D. Determinants of maternal health care utilization in Holeta town, central Ethiopia. BMC Health Serv Res. 2013; 13(256):10.

21. Tadesse E. Antenatal care service utilization of pregnant women attending antenatal care in public hospitals during the COVID-19 pandemic period. International Journal of Women's Health. 2020;12:1181.

22. Bahilu Tewodros, Abebe G/Mariam and Yohannes Dibaba. Factors Affecting Antenatal Care Utilization in Yem special woreda, Southern Nation's Nationalities and People Region Health Bureau Ethiopia, Ethiop J Health Sci. 2009: Vol. 19, No. 1

23. Birhanu Darega Gela,Nagasa Dida Bedada, Fikru Tafese Jaleta, and Shimeles Ololo Sinkie. Antenatal Care Utilization and Associated Factors from Rural Health Extension Workers in Abuna Gindeberet District, West Shewa, Oromiya Region, Ethiopia. American Journal of Health Research. 2012: Vol. 2, No. 4, pp. 113-11

24. Gurmesa Tura. 'Antenatal care service utilization and associated factors in Metekel Zone, Northwest Ethiopia', Ethiopia Journal health science. 2009: vol. 19, No. 2,.Pp 45-48

25. Tewodros Alemayehu, Jemal Haidar and Dereje Habte. Utilization of antenatal care services among teenagers in Ethiopia: A cross sectional study Ethiop. J. Health Dev. 2010: 24(3) 
26. Ejigu Tadese, Woldie Mirkuzie, Kifle Yibeltal. Quality of antenatal care services at public health facilities of Bahir-Dar special zone. Northwest Ethiopia BMC Health Services Research. 2013;13(443):2-8.

27. Muluneh AG, Kassa GM, Alemayehu GA, MeridMW(2020) High dropout rate from maternity continuum of care after antenatal care booking and its associated factors among reproductive age women in Ethiopia, Evidence from Demographic and Health Survey 2016. PLoS ONE 15(6): e0234741

28. Edgard-Marius O, Charles SJ, Jacques S, Justine GC-C, Virginie MA, Ibrahim $\mathrm{MA}$, et al. Determinants of low antenatal care services utilization during the first trimester of pregnancy in southern Benin rural setting. Universal J Public Health. 2015;3(5):220-8.

29. Terfasa TG, Afework MF, Berhe FT. Antenatal Care Utilization and It's Associated Factors in East Wollega Zone, Ethiopia. Preg Child Health. 2017;4.)

30. Sema A, Belay Y, Solomon Y, Desalew A, Misganaw A, Menberu T, Sintayehu Y, Getachew Y, Guta A, Tadesse D. Minimum Dietary Diversity Practice and Associated Factors among Children Aged 6 to 23 Months in Dire Dawa City, Eastern Ethiopia: A Community-Based Cross-Sectional Study. Global Pediatric Health. 2021 Feb;8:2333794 × 21996630

31. Department of Obstetrics and Gynecology, Faculty of Medicine Addis Ababa University. Management Guideline on Selected Topics in Obstetrics and Gynecology.Addis Ababa, Ethiopia. Feb,2004.

32. Amsalu Nemera Yabo, Mitsiwat Abebe Gebremicheal, Eshetu Ejeta Chaka. Assessment of Quality of Antenatal Care (ANC) Service Provision Among Pregnant Women in Ambo Town Public Health Institution, Ambo, Ethiopia. American Journal of Nursing Science. 2015, Vol. 4, No. 3,pp. 57-62.

33. Central Statistical Agency [Ethiopia]. Ethiopia mini demographic and health survey 2014

34. Singh DR, Jha T. Exploring factors influencing antenatal care visit dropout at government health facilities of Dhanusha District. Nepal Am J Public Health. 2016:4(5):170-5

35. Mulat G, Kassaw T, Aychiluhim M. Antenatal care service utilization and its associated factors among mothers who gave live birth in the past one year in Womberma Woreda, North West Ethiopia. Epidemiology (sunnyvale) S. 2015;2(003)

36. Ejigu T, Woldie M, Kifle Y. Quality of antenatal care services at public health facilities of Bahir-Dar special zone, Northwest Ethiopia. BMC health services research. 2013 Dec:13(1):1-8.

37. Tariku A, Melkamu Y, Kebede Z. Previous utilization of service does not improve timely booking in antenatal care: cross sectional study on timing of antenatal care booking at public health facilities in Addis Ababa. Ethiopian Journal of Health Development. 2010;24(3).

\section{Publisher's Note}

Springer Nature remains neutral with regard to jurisdictional claims in published maps and institutional affiliations.

Ready to submit your research? Choose BMC and benefit from:

- fast, convenient online submission

- thorough peer review by experienced researchers in your field

- rapid publication on acceptance

- support for research data, including large and complex data types

- gold Open Access which fosters wider collaboration and increased citations

- maximum visibility for your research: over $100 \mathrm{M}$ website views per year

At $\mathrm{BMC}$, research is always in progress.

Learn more biomedcentral.com/submissions 